\title{
ADENOCARCINOMA OF THE PROSTATE IN PARAPLEGICS
}

\author{
By Thomas Y. Ito and M. Menta \\ Long Beach Veteran's Administration Hospital, Long Beach, California, and the University \\ of California, Irvine, Dept. of Surgery (Urology)
}

\begin{abstract}
ADENOCARCINOMA of the prostate is rarely seen in paraplegics. No cases have been reported previously in the literature, except those found at autopsy. The first two cases seen in the Spinal Cord Injury Service (SCIS) at Long Beach Veteran's Hospital are presented here.
\end{abstract}

\section{Case Reports}

I. B. D., a 66-year-old white male, suffered crainiocerebral and L4 trauma in 1962 in an automobile accident. He had been followed at LBVAH for intermittent urinary tract infections secondary to a neurogenic bladder. He was admitted in May I974 with a history of low-grade fevers and cloudy urine. Physical examination revealed a somewhat obese male with a temperature of $100^{\circ} \mathrm{F}$. No CVA tenderness was present. Initial laboratory data included: CBC, Hct. 39 per cent WBC I0,000; and urinalysis revealed too numerous to count WBC's. A urine culture revealed Proteus and Pseudamonas and the patient was started on antibiotic therapy. Further work-up included an IVP which revealed a left staghorn calculus and a nonfunctioning kidney on that side.

Sometime after admission, the patient complained of left hip pain. X-rays revealed a fractured left femur with blastic lesions. A urology consult was obtained and a rockhard prostate with extension to the left was noted. An acid phosphatase was 28 (nl. to $0 \cdot 8$ ) and bone scan confirmed the blastic lesions. A prostatic needle biopsy was performed which revealed carcinoma of the prostate (fig. Ia). The patient was placed on diethylstilbesterol. Shortly thereafter he began to deteriorate with sepsis complicated by congestive heart failure, and a rising BUN and creatinine. He expired on 23 September 1974.

A postmortem examination revealed adenocarcinoma of the prostate with metastases to the bladder, pelvic floor, pericardium, left and right atrial appendages, adrenals, subpleural tissues and left testicle. In addition, severe bilateral hydronephrosis was present. Histologic sections of the tumour revealed poorly differentiated carcinoma of the prostate (fig. Ib).

2. H. M., a 53-year-old white male is a $\mathrm{C}_{7}$ paraplegic secondary to an automobile accident in I97I. He was admitted to LBVAH in June I974 with a history of difficulty emptying his bladder for one month. Two years prior to admission, the patient had had a transurethral resection of his prostate with a sphincterotomy. Physical examination revealed an alert, oriented male and was normal except for his myelopathy. His prostate was grade one-half without nodules. Laboratory data included: CBC, Hct. 38 per cent, WBC 8600; Urinalysis I0-I5 WBC's. SMA-6 and SMA-I2 were within normal limits. Acid phosphatase was 0.3 and 0.2 on two separate determinations (nl. to 0.8 ). A cystoscopy revealed an obstructive prostrate and he underwent a transurethral resection of his prostate, with removal of about Io grams of tissue.

Microscopic examination of the tissue revealed adenocarcinoma of the prostate (fig. 2). This was confirmed by the Armed Forces Institute of Pathology. The patient was placed on the Veteran's Administration Cooperative Research Group (Prostatic Cancer Protocol). Further workup including a bone scan and metastastic bone survey were negative.

I4/2-A 


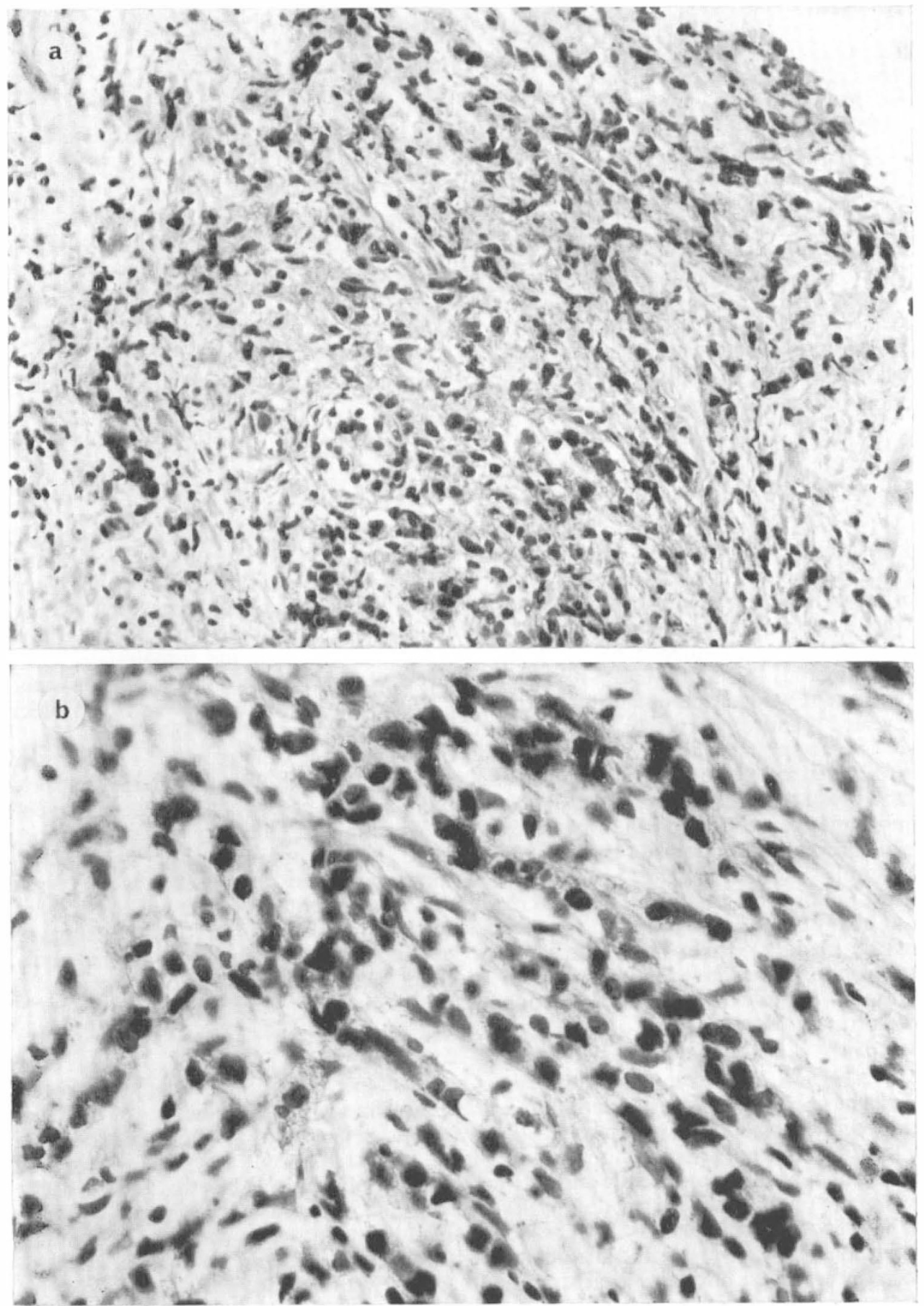

FIG. Ia

Prostatic needle biopsy specimen, high power. Note back-to-back glands.

FIG. Ib

High power view of specimen of metastatic lesion. Note pyknotic, irregular nuclei. 


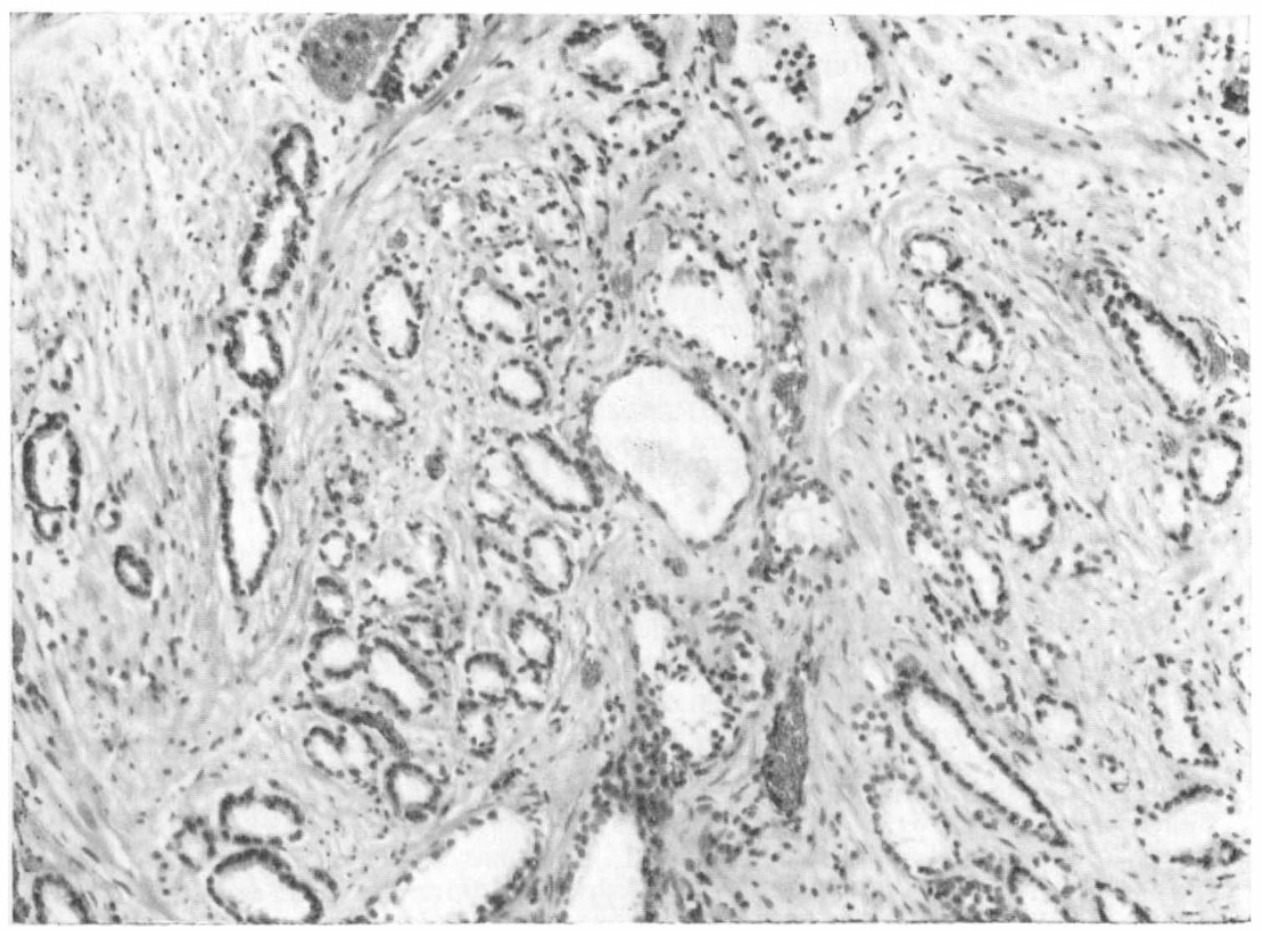

FIG. 2

Low-power view of prostatic tissue from transurethral resection.

\section{Discussion}

The relationship between spinal cord injuries and carcinoma of the prostate is uncertain. Whether the lack of reported cases is due to a lower incidence or lack of recognition remains to be seen. On one hand, an argument could be made that paraplegics, due to complications of their disease, die of other causes before carcinoma of the prostate becomes manifest. With improved survival, however, more cases may be found.

Huggins et al. in I939 and I94I showed the effects of hormones, especially androgens, on the prostate. It has been known for some time that there is a relationship between lesions of the spinal cord and testicular atrophy. For example, over 50 per cent of men with traumatic lesions of the spinal cord exhibit decreased spermatogenesis. Microscopically, arrested spermatogenesis is seen with normal Leydig cells. Some feel that an intact pituitary hypothalamic-spinalperipheral pathway may be necessary for maturation of sperm (Bustamente, 1942). Others feel that the atrophy seen is due to hyperthermia due to loss of sympathetic innervation (Bors et al., 1950).

Studies have been done regarding the hormonal derangements in paraplegics. For example, low levels of urinary gonadotropins have been reported in paraplegics (Paulsen, 1968). However, a study by Mizutani et al. of fifty-one paraplegics compared to normal controls revealed that although testicular volumes of paraplegics were significantly lower than in normals, the level of serum testosterone was not significantly higher or lower in paraplegics. 
Whether spinal cord lesions do in some fashion exert a 'protective' effect against the development of carcinoma of the prostate requires more study. As survival in paraplegics improves, more data with better diagnosis should be available in the near future. Physicians dealing with paraplegics should not overlook this diagnosis.

\section{ZUSAMMENFASSUNG}

Zwei Fälle von Adenokarzinom der Prostata werden beschrieben.

\section{RÉSUMÉ}

Deux cas de Adenocarcinoma du prostata sont reporte.

\section{REFERENCES}

Bors, E., Engle, E., Rosenquist, R. C. \& Holliger, V. H. (I950). Fertility in paraplegic males. F. Clin. Endo. I0, $38 \mathrm{I}$.

Bustamente, M. (1942). Experimentelle Untersuchungen, uber die Leistungen des Hypothalamus, Besonders bezüglich der Geschlechtsreifung. Arch. Psychiat. II 5, 419.

HugGINS, C. \& Hodges, C. V. (I94I). Studies on pratatic cancer: effect of castration, of estrogen, and androgen injection on serum phosphatases in carcinoma of the prostate. Cancer Research, I, 293.

Huggins, C., Masina, M. H., Eichelberger, L. \& Wharton, J. D. (I939). Quantitative studies of prostatic secretion, influence of thyroid, suprarenal, and testes extirpation and androgen substitution on prostatic output. F. $\operatorname{Exp}$. Med. 70, 543.

Mizutani, S., Sonoda, T., Matsumoto, K. \& IwASA, K. (1972). Plasma testosterone concentrations in paraplegic man. F. Endocrinology, 54, 363-364.

Paulsen, C. A. (I968). Textbook of Endocrinology, 405-458. 